\title{
Citations to articles of this issue:
}

Badman, S., Auroral signatures of Saturn's magenetospheric dynamics (abstract), in Planetary Radio Emissions VIII, edited by G. Fischer, G. Mann, M. Panchenko, and P. Zarka, Austrian Academy of Sciences Press, Vienna, p.221, 2017.

Burinskaya, T. M., and M. M. Shevelev, Generation of Auroral Kilometric Radiation in a dipole magnetic field: 3-D approach, in Planetary Radio Emissions VIII, edited by G. Fischer, G. Mann, M. Panchenko, and P. Zarka, Austrian Academy of Sciences Press, Vienna, 261-268, 2017.

Cecconi, B., P. Zarka, R. Savelle, P. Le Sidnaer, A. Coffre, L. Denis, C. Viou, A. Konovalenko, A. Skoryk, S. Yerin, Y. Kasaba, A. Kumamoto, H. Misawa, T. Tsuchiya, Y. Hobara, T. Nakajo, K. Imai, V. Ryabov, H. Rothkaehl, G. S. Orton, T. Momary, J.-M. Grießmeier, M. Imai, J. N. Girard, L. Lamy, M. Anderson, N. André, V. Génot, R. Ebert, T. Carozzi, T. Kimura, W. S. Kurth, C. A. Higgins, J. L. Mugler, D. Typinsky, T. Clarke, J. Sky, R. Flagg, F. Reyes, W. Greenman, J. Brown, A. Mount, T. Ashcraft, J. Thieman, W. Reeve, S. Fung, N. Towne, T. King, and S. Bolton, Juno-ground-radio observations support (abstract), in Planetary Radio Emissions VIII, edited by G. Fischer, G. Mann, M. Panchenko, and P. Zarka, Austrian Academy of Sciences Press, Vienna, pp.27, 2017.

Cecconi, B., A. Pruvot, L. Lamy, P. Zarka, C. Louis, S. L. G. Hess, D. R. Evans, and D. Boucon, Refurbishing Voyager 1 \& 2 Planetary Radio Astronomy (PRA) data, in Planetary Radio Emissions VIII, edited by G. Fischer, G. Mann, M. Panchenko, and P. Zarka, Austrian Academy of Sciences Press, Vienna, 505-514, 2017.

Clarke, T.E., C. A. Higgins, M. Imai, and K. Imai, Jovian decametric emission with the Long Wavelength Array station 1 (LWA1), in Planetary Radio Emissions VIII, edited by G. Fischer, G. Mann, M. Panchenko, and P. Zarka, Austrian Academy of Sciences Press, Vienna, 31-44, 2017.

Dạbrowski, B. P., L. Błaszkiewicz, A. Krankowski, D. E. Morosan, K. Kotulak, A. Froń, and T. Sidorowicz, Low frequency solar scrutiny with the Polish LOFAR stations, in Planetary Radio Emissions VIII, edited by G. Fischer, G. Mann, M. Panchenko, and P. Zarka, Austrian Academy of Sciences Press, Vienna, 437-444, 2017.

Dorovskyy, V., V. Melnik, A. Konovalenko, A. Brazhenko, S. Poedts, H. Rucker, and M. Panchenko, Properties of groups of solar S-bursts in the decameter band, in Planetary Radio Emissions VIII, edited by G. Fischer, G. Mann, M. Panchenko, and P. Zarka, Austrian Academy of Sciences Press, Vienna, 369-378, 2017.

Enriquez, J. E., G. Ramsay, P. Zarka, and H. Falcke, Searching for brown dwarfs at low radio frequencies (abstract), in Planetary Radio Emissions VIII, edited by G. Fischer, G. Mann, M. Panchenko, and P. Zarka, Austrian Academy of Sciences Press, Vienna, p.331, 2017.

Fischer, G., B. Cecconi, J. Bergman, J. Girard, G. Quinsac, and J.-E. Wahlund, Short antennas on a large spacecraft, in Planetary Radio Emissions VIII, edited by G. Fischer, G. Mann, M. Panchenko, and P. Zarka, Austrian Academy of Sciences Press, Vienna, 515-523, 2017. 
Grießmeier, J.-M., The search for radio emission from giant exoplanets, in Planetary Radio Emissions VIII, edited by G. Fischer, G. Mann, M. Panchenko, and P. Zarka, Austrian Academy of Sciences Press, Vienna, 285-299, 2017.

Gubchenko, V.M., On the efficiency of the source of electromagnetic emission in the electron diffusion region formed by plasma flow (extended abstract), in Planetary Radio Emissions VIII, edited by G. Fischer, G. Mann, M. Panchenko, and P. Zarka, Austrian Academy of Sciences Press, Vienna, pp.279, 2017.

Hatch, S. M., and J. LaBelle, Application of a new method for calculation of low-frequency wave vectors, in Planetary Radio Emissions VIII, edited by G. Fischer, G. Mann, M. Panchenko, and P. Zarka, Austrian Academy of Sciences Press, Vienna, 247-259, 2017.

Helling, Ch., and I. Vorgul, Insight into atmospheres of extrasolar planets through plasma processes, in Planetary Radio Emissions VIII, edited by G. Fischer, G. Mann, M. Panchenko, and P. Zarka, Austrian Academy of Sciences Press, Vienna, 335-343, 2017.

Hess, S. L. G., B. Bonfond, F. Bagenal, and L. Lamy, A model of the Jovian internal field derived from in-situ and auroral constraints, in Planetary Radio Emissions VIII, edited by G. Fischer, G. Mann, M. Panchenko, and P. Zarka, Austrian Academy of Sciences Press, Vienna, 157-167, 2017.

Higgins, C., T. E. Clarke, K. Imai, M. Imai, F. Reyes, and J. Thieman, Morphology of the Jupiter Io-D decametric radio source, in Planetary Radio Emissions VIII, edited by G. Fischer, G. Mann, M. Panchenko, and P. Zarka, Austrian Academy of Sciences Press, Vienna, 77-88, 2017.

Higgins, C., J. Thieman, S. Fung, F. Reyes, D. Typinski, W. Greenman, R. Flagg, J. Brown, T. Ashcraft, N. Towne, J. Sky, L. Garcia, and B. Cecconi, The Radio Jove Project: Citizen science for radio astronomy (abstract), in Planetary Radio Emissions VIII, edited by G. Fischer, G. Mann, M. Panchenko, and P. Zarka, Austrian Academy of Sciences Press, Vienna, p.125, 2017.

Hodosán, G., Ch. Helling, and P.B. Rimmer, Exo-lightning radio emission: The case study of HAT-P-11b, in Planetary Radio Emissions VIII, edited by G. Fischer, G. Mann, M. Panchenko, and P. Zarka, Austrian Academy of Sciences Press, Vienna, 345-356, 2017.

Hospodarsky, G. B., M. Imai, W. S. Kurth, D. A. Gurnett, and S. J. Bolton, Quasi-periodic (QP) emissions as observed by Juno Waves (abstract), in Planetary Radio Emissions VIII, edited by G. Fischer, G. Mann, M. Panchenko, and P. Zarka, Austrian Academy of Sciences Press, Vienna, p.25, 2017.

Imai, K., C. A. Higgins, M. Imai, and T. E. Clarke, Jupiter's Io-C and Io-B decametric emission source morphology from LWA1 data analysis, in Planetary Radio Emissions VIII, edited by G. Fischer, G. Mann, M. Panchenko, and P. Zarka, Austrian Academy of Sciences Press, Vienna, 89-101, 2017. 
Imai, M., W. S. Kurth, G. B. Hospodarsky, D. A. Gurnett, S. J. Bolton, J. E. P. Connerney, S. M. Levin, P. Zarka, B. Cecconi, A. Lecacheux, and L. Lamy, Analysis of Jovian low-frequency radio emissions based on stereoscopic observations with Juno and Earth-based radio telescopes, in Planetary Radio Emissions VIII, edited by G. Fischer, G. Mann, M. Panchenko, and P. Zarka, Austrian Academy of Sciences Press, Vienna, 13-23, 2017.

Jackman, C., J. J. Reed, D. Whiter, L. Lamy, and W. S. Kurth, How do Saturn's radio emissions respond to magnetospheric compressions and tail reconnection: An analysis of SKR burst and low frequency extensions (LFEs) (abstract), in Planetary Radio Emissions VIII, edited by G. Fischer, G. Mann, M. Panchenko, and P. Zarka, Austrian Academy of Sciences Press, Vienna, p.219, 2017.

Kalinichenko, N. N., M. R. Olyak, A. A. Konovalenko, R. Fallows, P. Zarka, H. O. Rucker, A. Lecacheux, I. N. Bubnov, S. N. Yerin, A. I. Brazhenko, O. L. Ivantishin, V. V. Koshovy, and O. A. Lytvynenko, The investigations of the solar wind beyond Earth's orbit by IPS observations at decameter wavelengths: Present state and perspectives, in Planetary Radio Emissions VIII, edited by G. Fischer, G. Mann, M. Panchenko, and P. Zarka, Austrian Academy of Sciences Press, Vienna, 479-486, 2017.

Kasaba, Y., T. Kimura, D. Maruno, A. Morioka, B. Cecconi, L. Lamy, C. M. Jackman, C. Tao, H. Kita, H. Misawa, T. Tsuchiya, and A. Kumamoto, A flux comparison of northern and southern Saturn kilometric radio bursts during southern summer, in Planetary Radio Emissions VIII, edited by G. Fischer, G. Mann, M. Panchenko, and P. Zarka, Austrian Academy of Sciences Press, Vienna, 205-215, 2017.

Katoh, Y., H. Kojima, K. Asamura, Y. Kasaba, F. Tsuchiya, Y. Kasahara, T. Imachi, H. Misawa, A. Kumamoto, S. Yagitani, K. Ishisaka, T. Kimura, M. Hikishima, Y. Miyoshi, M. Shoji, M. Kitahara, O. Santolik, J. Bergman, W. Puccio, R. Gill, M. Wieser, W. Schmidt, S. Barabash, and J.-E. Wahlund, Software-type WaveParticle Interaction Analyzer (S-WPIA) by RPWI for JUICE: Science objectives and implementation, in Planetary Radio Emissions VIII, edited by G. Fischer, G. Mann, M. Panchenko, and P. Zarka, Austrian Academy of Sciences Press, Vienna, 495-504, 2017.

Khodachenko, M., I.-F. Shaikhislamov, I. I. Alexeev, E. S. Belenkaya, and H. Lammer, Magnetospheres of Hot Jupiters: On the physical phenomena potentially observable in radio (abstract), in Planetary Radio Emissions VIII, edited by G. Fischer, G. Mann, M. Panchenko, and P. Zarka, Austrian Academy of Sciences Press, Vienna, pp.315, 2017.

Kimura, T., G. Murakami, Y. Yamazaki, F. Tsuchiya, K. Yoshioka, C. Tao, H. Kita, S. V. Badman, M. Fujimoto, and the Hisaki Science Team, Continuous monitoring of Jupiter's aurora and Io plasma torus with the Hisaki satellite: Recent results and future coordination with Juno (abstract), in Planetary Radio Emissions VIII, edited by G. Fischer, G. Mann, M. Panchenko, and P. Zarka, Austrian Academy of Sciences Press, Vienna, p.29, 2017. 
Knapp, M., D. Winterhalter, and T. Bastian, Getting to know the nearest stars: Intermittent radio emission from Ross 614 (abstract), in Planetary Radio Emissions VIII, edited by G. Fischer, G. Mann, M. Panchenko, and P. Zarka, Austrian Academy of Sciences Press, Vienna, p.333, 2017.

Knapp, M., D. E. Gary, M. H. Hecht, C. Lonsdale, F. D. Lind, F. C. Robey, L. Fuhrman, B. Chen, A. J. Fenn, and the HeRO team, HeRO: A space-based low frequency interferometric observatory for heliophysics enabled by novel vector sensor technology, in Planetary Radio Emissions VIII, edited by G. Fischer, G. Mann, M. Panchenko, and P. Zarka, Austrian Academy of Sciences Press, Vienna, 411-423, 2017.

Kolmasova, I., O. Santolik, and A. Skalsky, Anticipated plasma wave measurement onboard ExoMars 2020 surface platform, in Planetary Radio Emissions VIII, edited by G. Fischer, G. Mann, M. Panchenko, and P. Zarka, Austrian Academy of Sciences Press, Vienna, 487-493, 2017.

Konovalenko, A., P. Zarka, H. O. Rucker, V. Zakharenko, O. Ulyanov, M. Sidorchuk, S. Stepkin, V. Melnik, N. Kalinichenko, A. Stanislavsky, P. Tokarsky, V. Koliadin, V. Shepelev, V. Dorovskyy, I. Bubnov, S. Yerin, A. Reznichenko, G. Litvinenko, N. Shevchuk, A. Koval, I. Vasylieva, K. Mylostna, A. Skoryk, A. Shevtsova, Y. Volvach, E. Vasylkovsky, V. Ryabov, A. Lecacheux, L. Denis, M. Panchenko, G. Fischer, M. Imai, J.-M. Grießmeier, G. Mann, O. Litvinenko, A. Brazhenko, R. Vashchishin, A. Frantsuzenko, V. Koshovy, A. Lozinsky, and O. Ivantyshin, Mulit-antenna observations in the low-frequency radio astronomy of solar system objects and related topics studies, in Planetary Radio Emissions VIII, edited by G. Fischer, G. Mann, M. Panchenko, and P. Zarka, Austrian Academy of Sciences Press, Vienna, 467-478, 2017.

Krupar, V., O. Santolik, J. Soucek, O. Kruparova, M. Maksimovic, E. Kontar, and J. Eastwood, Interplanetary type III bursts and density fluctuations in the solar wind (abstract), in Planetary Radio Emissions VIII, edited by G. Fischer, G. Mann, M. Panchenko, and P. Zarka, Austrian Academy of Sciences Press, Vienna, p.407, 2017.

Kumamoto, A., Y. Kasaba, F. Tsuchiya, H. Misawa, H. Kita, W. Puccio, J.-E. Wahlund, J. Bergman, B. Cecconi, Y. Goto, J. Kimura, and T. Kobayashi, Feasibility of the exploration of the subsurface structures of Jupiter's icy moons by interference of Jovian hectometric and decametric radiation, in Planetary Radio Emissions VIII, edited by G. Fischer, G. Mann, M. Panchenko, and P. Zarka, Austrian Academy of Sciences Press, Vienna, 127-136, 2017.

Kumamoto, A., S. Kakimoto, Y. Sasaki, H. Misawa, Y. Katoh, F. Tsuchiya, and B. Cecconi, Statistical analysis of periodicity of Jovian S-burst (abstract), in Planetary Radio Emissions VIII, edited by G. Fischer, G. Mann, M. Panchenko, and P. Zarka, Austrian Academy of Sciences Press, Vienna, p.119, 2017.

Kurth, W.S., M. Imai, G. B. Hospodarsky, D. A. Gurnett, S. S. Tetrick, S.-Y. Ye, S. J. Bolton, J. E. P. Connerney, and S. M. Levin, First observations near Jupiter by the Juno Waves investigation, in Planetary Radio Emissions VIII, edited by G. Fischer, G. Mann, M. Panchenko, and P. Zarka, Austrian Academy of Sciences Press, Vienna, $1-12,2017$. 
LaBelle, J., High electron cyclotron harmonic emissions from aurora (abstract), in Planetary Radio Emissions VIII, edited by G. Fischer, G. Mann, M. Panchenko, and P. Zarka, Austrian Academy of Sciences Press, Vienna, p.245, 2017.

Lamy, L., The Saturnian Kilometric Radiation before the Cassini Grand Finale, in Planetary Radio Emissions VIII, edited by G. Fischer, G. Mann, M. Panchenko, and P. Zarka, Austrian Academy of Sciences Press, Vienna, 171-190, 2017.

Lamy, L., Search for Io, Ganymede and Europa induced radio emissions from Cassini/RPWS integrated power time series (abstract), in Planetary Radio Emissions VIII, edited by G. Fischer, G. Mann, M. Panchenko, and P. Zarka, Austrian Academy of Sciences Press, Vienna, p.73, 2017.

Lamy, L., P. Zarka, B. Cecconi, L. Klein, S. Masson, L. Denis, A. Coffre, and C. Viou, 1977-2017: 40 years of decametric observations of Jupiter and the Sun with the Nançay Decameter Array, in Planetary Radio Emissions VIII, edited by G. Fischer, G. Mann, M. Panchenko, and P. Zarka, Austrian Academy of Sciences Press, Vienna, 455-466, 2017.

Lecacheux, A., M. Imai, T. Clarke, C. Higgins, M. Panchenko, A. Konovalenko, and A. Brazhenko, Jovian DAM linear polarization study from coordinated, distant, ground-based radio telescopes (abstract), in Planetary Radio Emissions VIII, edited by G. Fischer, G. Mann, M. Panchenko, and P. Zarka, Austrian Academy of Sciences Press, Vienna, p.121, 2017.

Litvinenko, G., A. Konovalenko, V. Zakharenko, I. Vasylieva, P. Zarka, A. Lecacheux, V. Shaposhnikov, H. O. Rucker, M. Panchenko, and O. Ulyanov, Analysis of the observational characteristics of shadow-effects in the Jovian DAM emission (abstract), in Planetary Radio Emissions VIII, edited by G. Fischer, G. Mann, M. Panchenko, and P. Zarka, Austrian Academy of Sciences Press, Vienna, p.123, 2017.

Lonsdale, C., L. Benkevitch, I. Cairns, M. Crowley, P. Erickson, M. Knapp, K. Kovarev, F. Lind, P. McCauley, J. Morgan, and D. Oberoi, Solar imaging using low frequency arrays, in Planetary Radio Emissions VIII, edited by G. Fischer, G. Mann, M. Panchenko, and P. Zarka, Austrian Academy of Sciences Press, Vienna, 425-434, 2017.

Lou, Y.-Q., Quasi-periodic magnetospheric activities of Jupiter and Saturn and magnetoinertial oscillations of their inner radiation belts (extended abstract), in Planetary Radio Emissions VIII, edited by G. Fischer, G. Mann, M. Panchenko, and P. Zarka, Austrian Academy of Sciences Press, Vienna, pp.151, 2017.

Louis, C. K., L. Lamy, P. Zarka, B. Cecconi, S. L. G. Hess, and X. Bonnin, Simulating Jupiter-satellite decametric emissions with ExPRES: A parametric study, in Planetary Radio Emissions VIII, edited by G. Fischer, G. Mann, M. Panchenko, and P. Zarka, Austrian Academy of Sciences Press, Vienna, 59-72, 2017.

Mann, G., C. Vocks, F. Breitling, LOFAR's Solar KSP team, and the LOFAR team at ASTRON, Observations of the Sun with the radio telescope LOFAR (abstract), in Planetary Radio Emissions VIII, edited by G. Fischer, G. Mann, M. Panchenko, and P. Zarka, Austrian Academy of Sciences Press, Vienna, p.379, 2017. 
Marek, M., and R. Schreiber, Is the AKR Cyclotron Maser Instability a self-organized criticality system? in Planetary Radio Emissions VIII, edited by G. Fischer, G. Mann, M. Panchenko, and P. Zarka, Austrian Academy of Sciences Press, Vienna, 269-277, 2017.

Marques, M.S., P. Zarka, E. Echer, V. B. Ryabov, and M. V. Alves, Statistical analysis of 26 years of observations of decametric radio emissions from Jupiter (abstract), in Planetary Radio Emissions VIII, edited by G. Fischer, G. Mann, M. Panchenko, and P. Zarka, Austrian Academy of Sciences Press, Vienna, p.75, 2017.

Melnik, V. N., A. I. Brazhenko, G. Mann, A. A. Konovalenko, A. V. Frantsuzenko, H. O. Rucker, and M. Panchenko, Radio manifestation of the CME observed on April 7, 2011 in the frequency band 8-32 MHz, in Planetary Radio Emissions VIII, edited by G. Fischer, G. Mann, M. Panchenko, and P. Zarka, Austrian Academy of Sciences Press, Vienna, 381-390, 2017.

Misawa, H., F. Tsuchiya, T. Kimura, Y. Kasaba, and A. Kumamoto, Variation characteristics of Jupiter's hectometric radiation during the Iogenic plasma enhancement period (abstract), in Planetary Radio Emissions VIII, edited by G. Fischer, G. Mann, M. Panchenko, and P. Zarka, Austrian Academy of Sciences Press, Vienna, p.137, 2017.

Morosan, D.E., and P.T. Gallagher, Characteristics of type III radio bursts and solar S bursts, in Planetary Radio Emissions VIII, edited by G. Fischer, G. Mann, M. Panchenko, and P. Zarka, Austrian Academy of Sciences Press, Vienna, 357-368, 2017.

Mulay, S. M., D. Tripathi, G. Del Zanna, and H. Mason, An active region jet and associated type III radio burst (extended abstract), in Planetary Radio Emissions VIII, edited by G. Fischer, G. Mann, M. Panchenko, and P. Zarka, Austrian Academy of Sciences Press, Vienna, pp.403, 2017.

Mylostna, K. Y., V. V. Zakharenko, G. Fischer, A. A. Konovalenko, and P. Zarka, Study of SED's emission parameters, in Planetary Radio Emissions VIII, edited by G. Fischer, G. Mann, M. Panchenko, and P. Zarka, Austrian Academy of Sciences Press, Vienna, 223-231, 2017.

Panchenko, M., S. Rosker, H. O. Rucker, A. Brazhenko, A. A. Konovalenko, G. Litvinenko, P. Zarka, V. Melnik, V. E. Shaposhnikov, and A. V. Frantsuzenko, Zebra-like fine spectral structures in Jovian decametric radio emission, in Planetary Radio Emissions VIII, edited by G. Fischer, G. Mann, M. Panchenko, and P. Zarka, Austrian Academy of Sciences Press, Vienna, 103-115, 2017.

Santolik, O., J. Soucek, I. Kolmasova, G. B. Hospodarsky, W. S. Kurth, C. A. Kletzing, and J.-E. Wahlund, Whistler-mode chorus and hiss in the inner magnetosphere of Earth: Consequences for the JUICE project (abstract), in Planetary Radio Emissions VIII, edited by G. Fischer, G. Mann, M. Panchenko, and P. Zarka, Austrian Academy of Sciences Press, Vienna, p.243, 2017.

Sasaki, A., Y. Kasaba, T. Kimura, C. Tao, L. Lamy, and B. Cecconi, Seasonal variation of Saturn's auroral radio emissions in 2004-2015: The correlation with solar wind 
activity and solar EUV flux (abstract), in Planetary Radio Emissions VIII, edited by G. Fischer, G. Mann, M. Panchenko, and P. Zarka, Austrian Academy of Sciences Press, Vienna, pp.217, 2017.

Schiemel, J., M. Panchenko, H. O. Rucker, A.I. Brazhenko, and A. A. Konovalenko, Jupiter radio fine structures observed in decametric frequency range by URAN-2 radio telescope (abstract), in Planetary Radio Emissions VIII, edited by G. Fischer, G. Mann, M. Panchenko, and P. Zarka, Austrian Academy of Sciences Press, Vienna, p.117, 2017.

Shaposhnikov, V., G. Litvinenko, H. O. Rucker, V. Zaitsev, and A. Konovalenko, Io's ultraviolet spot emission as a probe of the Jovian magnetic field model (abstract), in Planetary Radio Emissions VIII, edited by G. Fischer, G. Mann, M. Panchenko, and P. Zarka, Austrian Academy of Sciences Press, Vienna, p.169, 2017.

Stanislavsky, A. A., A. A. Konovalenko, Ya.S. Volvach, and A. A. Koval, Brightness temperature of decameter solar bursts with high-frequency cut-off, in Planetary Radio Emissions VIII, edited by G. Fischer, G. Mann, M. Panchenko, and P. Zarka, Austrian Academy of Sciences Press, Vienna, 391-401, 2017.

Stanislavsky, A. A., A. A. Konovalenko, A. A. Koval, E. P. Abranin, Ya. S. Volvach, and L. A. Stanislavsky, Progress in solar radio imaging with the UTR-2 radio telescope at decameter wavelengths (abstract), in Planetary Radio Emissions VIII, edited by G. Fischer, G. Mann, M. Panchenko, and P. Zarka, Austrian Academy of Sciences Press, Vienna, p.435, 2017.

Tao, C., L. Lamy, R. Prangé, N. André, and S. V. Badman, Auroral electron energy estimation using the $\mathrm{H} / \mathrm{H}_{2}$ brightness ratio applied to Jupiter, in Planetary Radio Emissions VIII, edited by G. Fischer, G. Mann, M. Panchenko, and P. Zarka, Austrian Academy of Sciences Press, Vienna, 139-149, 2017.

Taubenschuss, U., A.G. Demekhov, and O. Santolik, Interpretation of whistler mode chorus observations with the backward wave oscillator model, in Planetary Radio Emissions VIII, edited by G. Fischer, G. Mann, M. Panchenko, and P. Zarka, Austrian Academy of Sciences Press, Vienna, 233-242, 2017.

Treumann, R.A., and W. Baumjohann, The ECMI in turbulent reconnecting current layers in strong guide fields (abstract), in Planetary Radio Emissions VIII, edited by G. Fischer, G. Mann, M. Panchenko, and P. Zarka, Austrian Academy of Sciences Press, Vienna, p.283, 2017.

Tsuchiya, F., H. Misawa, T. Obara, K. Iwai, K. Kaneda, S. Matsumoto, A. Kumamoto, Y. Katoh, M. Yagi, and B. Cecconi, Database of solar radio bursts observed by solar radio spectro-polarimeter AMATERAS, in Planetary Radio Emissions VIII, edited by G. Fischer, G. Mann, M. Panchenko, and P. Zarka, Austrian Academy of Sciences Press, Vienna, 445-453, 2017.

Tsuchiya, F., H. Misawa, and H. Kita, Total flux measurements of Jupiter's synchrotron radiation during the Hisaki and Juno campaign periods (abstract), in Planetary Radio Emissions VIII, edited by G. Fischer, G. Mann, M. Panchenko, and P. Zarka, Austrian Academy of Sciences Press, Vienna, p.155, 2017. 
Turner, J. D., J.-M. Grießmeier, P. Zarka, and I. Vasylieva, The search for radio emission from exoplanets using LOFAR low-frequency beam-formed observations: Data pipeline and preliminary results for the 55 Cnc system, in Planetary Radio Emissions VIII, edited by G. Fischer, G. Mann, M. Panchenko, and P. Zarka, Austrian Academy of Sciences Press, Vienna, 301-313, 2017.

Weber, C., H. Lammer, I.-F. Shaikhislamov, J.-M. Chadney, N. Erkaev, M. L. Khodachenko, J.-M. Grießmeier, H. O. Rucker, C. Vocks, W. Macher, P. Odert and K.-G. Kislyakova, On the Cyclotron Maser Instability in magnetospheres of Hot Jupiters-Influence of ionosphere models, in Planetary Radio Emissions VIII, edited by G. Fischer, G. Mann, M. Panchenko, and P. Zarka, Austrian Academy of Sciences Press, Vienna, 317-329, 2017.

Ye, S.-Y., G. Fischer, W.S. Kurth, J.D. Menietti, and D. A. Gurnett, Rotational modulation of Saturn Kilometric Radiation, narrrowband emission and auroral hiss, in Planetary Radio Emissions VIII, edited by G. Fischer, G. Mann, M. Panchenko, and P. Zarka, Austrian Academy of Sciences Press, Vienna, 191-204, 2017.

Zaqarashvili, T., O.S. Pylaev, A. I. Brazhenko, V. N. Melnik, and A. Hanslmeier, Oscillation of solar radio emission at coronal acoustic cut-off frequency (abstract), in Planetary Radio Emissions VIII, edited by G. Fischer, G. Mann, M. Panchenko, and P. Zarka, Austrian Academy of Sciences Press, Vienna, p.409, 2017.

Zarka, P., M.S. Marques, C. Louis, V. B. Ryabov, L. Lamy, E. Echer, and B. Cecconi, Radio emission from satellite--Jupiter interactions (especially Ganymede), in Planetary Radio Emissions VIII, edited by G. Fischer, G. Mann, M. Panchenko, and P. Zarka, Austrian Academy of Sciences Press, Vienna, 45-58, 2017. 
